\title{
Quality, Reputation and the Choice of Organizational Form*
}

\author{
Michael Vlassopoulos ${ }^{\dagger}$
}

February 20, 2009

\begin{abstract}
This paper revisits the hypothesis that nonprofit organizations emerge in markets that are characterized by contractual incompleteness because they ensure consumers against opportunistic behavior. We extend the Glaeser and Shleifer (2001) framework which studies an entrepreneur's optimal choice of organizational form and service quality when quality is noncontractible into a repeated interaction setting. The main result is that when reputations can be sustained, then for-profit status is the preferred organizational form and high quality services are ensured. This finding suggests that existing explanations of nonprofit organizations that focus entirely on contractual imperfections in the producer/consumer relationship may be inadequate.
\end{abstract}

JEL Codes: L14, L30

Keywords: Nonprofit Status, Reputation, Contractual Incompleteness

${ }^{*}$ I am particularly grateful to Patrick Francois for numerous discussions and valuable suggestions. I also thank Ralph Winter and two anonymous referees for helpful comments. All errors are mine.

${ }^{\dagger}$ Economics Division, School of Social Sciences, University of Southampton, Southampton SO17 1BJ, UK. Tel.: +44238059 3268; Fax: +44 238059 3858. E-mail: M.Vlassopoulos@soton.ac.uk 


\section{Introduction}

The importance of the provision of high quality public services such as health, education, child care and care for the aged cannot be overstated. ${ }^{1}$ Clearly, voters and consequently their elected representatives place a high value on these, and improvements in these areas are given high priority in the social agenda of any modern society. However, several potential pathologies associated with the provision of such services have been recognized in the economics literature. In particular, one kind of market failure that has received considerable attention is the one induced by the high degree of information asymmetries between providers and consumers over the quality of these services. The problem arises when consumers are not as well informed about the quality of the service or when the quality of the service is difficult to measure and verify by third parties. In such circumstances, it is argued, service providers have an incentive to act opportunistically and take advantage of the ill-informed consumer. These informational problems are exacerbated by the fact that often the person who is consuming these services is not the person who is choosing them. For example, a parent chooses and pays for her child's schooling but is not the recipient of the services; moreover, the quality of the provided service may be hard to assess immediately because the potential deficiencies may manifest themselves only as the child grows up. ${ }^{2}$

In response to these informational problems, which following the literature we will refer to as "contractual failures", it has been suggested by some authors, starting with Hansmann (1980), ${ }^{3}$ that nonprofit organizations are an effective solution because the low-powered incentives that permeate the structure of these organizations provide insurance to the consumer that she is not going to be exploited. In other words, what this theory argues is that nonprofit organizations act as a commitment mechanism for the provision of quality services in circumstances where quality is too costly to monitor.

Interestingly, Hart et al. (1997) use a similar rationale in an influential paper that analyzes the choice between in-house government provision of services and contracting out to private suppliers, when the quality of service the government requires cannot be fully specified. The conclusion that emerges from their analysis is that private provision is generally more cost efficient but may

\footnotetext{
${ }^{1}$ These services are often more accurately characterized as quasi-public goods in that they yield both public and private benefits. In addition, the mere fact that the private sector is partly involved in the provision of these services indicates that they fail to satisfy (or do not satisfy fully) one or both of the principal properties associated with pure public goods: non-rivalry and non-excludability.

${ }^{2}$ This type of goods, which are evaluated by experience, are commonly referred to as experience goods (see Nelson 1970).

${ }^{3}$ Other early studies of nonprofit organizations that emphasize the role of asymmetric information between producers and consumers are Easly and O'Hara (1983) and Weisbrod (1988).
} 
result in lower quality service because private suppliers have a stronger incentive to undertake cost reduction that adversely affects quality. In a recent formalization of the "contractual failure" idea, Glaeser and Shleifer (2001) apply the incomplete contracts framework of Hart et al. to study the choice of an entrepreneur between setting up a for-profit firm and a nonprofit organization. The prediction of their model is that when the benefit of commitment is high, that is, when consumers value quality highly and are willing to pay higher prices anticipating better quality, then nonprofit status is preferable, despite the fact that the entrepreneur is not the full claimant of profits, because it ensures softer incentives to skimp on quality.

This paper is motivated by the fact that in spite of its intuitive appeal, the contractual failure approach seems to have overlooked a potentially important issue, namely, that the relationship between purchaser and supplier is, in many cases, an on-going one. The on-going aspect of the relationship should allow reputation to emerge as another mechanism for maintaining high unverifiable quality. ${ }^{4}$ Therefore, a potential limitation of the contractual failure argument is that it fails to take into account the interaction between reputations and the choice of organizational form or treats the two as orthogonal.

However, markets that involve unverifiable quality are exactly the ones where we would expect long-term relationships to predominate and reputation effects to matter. Specifically, the repeated feature of the interaction between producer and consumer seems particularly relevant in the case of public services, where the arrangement of services is typically of a continuing nature and rarely entails a one-time exchange. A related shortcoming of this theory arises when one considers a salient pattern in the sectoral concentration of nonprofits. In particular, contractual failures cannot be reconciled with the observation that nonprofit organizations tend to engage predominantly in the provision of health, education, social and other mission-oriented services and not other services where quality is equally unobservable and informational problems are acute (for example business, professional, legal services, etc.), yet, only for-profit firms appear to have established themselves as quality providers of services in the latter. Thus, two related questions can be raised: (a) Is it possible for reputation mechanisms to work equally well in the provision of public services and ensure the supply of quality services by for-profit firms? (b)What factors determine when reputation is a sufficient consumer protection mechanism and when not, in which case nonprofit status is necessary to resolve failures associated with informational imperfections?

The purpose of this paper is to address explicitly these questions by studying the optimal

\footnotetext{
${ }^{4}$ Word of mouth is also a means of learning about the quality of the services of various providers. Therefore, reputation is valuable not only because of the multiple purchases by the same person, but also through the impact of this person's experience on his friends and family.
} 
choice of organizational status allowing reputation to act as an alternative commitment mechanism to nonprofit status for the provision of high quality services. ${ }^{5}$ Our analysis builds on the Glaeser and Shleifer (2001) model because it captures the essence of the theory in a concise and formal way. A repeated game is the natural environment to study reputation effects. Therefore, we extend the one-shot framework to a setting of repeated interaction between the consumer and the provider of the service and establish conditions under which reputation is a sufficient mechanism for the provision of quality services by for-profit firms. The idea that repeated purchases are a means of disciplining the producer to deliver high quality has been previously explored in the Industrial Organization literature. ${ }^{6}$ The difference in our approach is that, besides quality, the choice of organizational form is endogenous and the interest is on what combination of type of firm and quality level will be optimally chosen in a dynamic set-up.

One may question whether adopting an infinite horizon framework is appropriate for our purposes, as some of the interactions between consumers and service providers in industries where nonprofits are present have a fixed and finite end. ${ }^{7}$ For instance, parents are interested in seeking child care services for a specific and known beforehand amount of time: until the child goes to school. Nevertheless, such examples can still be captured in an infinitely horizon setting if conceived as repeated games between a single long-lived firm that is facing a sequence of once-off or finite trades with a community of consumers who communicate with each other their experience with the firm and condition their behavior on the firm's behavior towards their predecessors. That is, in order for there to be an equilibrium of the repeated game where the firm produces high quality, only the player who is tempted to cheat (i.e. the firm providing child care services) need be infinitely-lived or strategically behave as he were so. Moreover, the literature on finitely repeated games has shown that under rather weak conditions, repeated games with a large but finite horizon behave similarly to infinitely repeated games (Benoit and Krishna 1985). That is, the intuitive argument that drives the folk theorems in infinitely repeated games can apply, with modification, to a large class of finitely repeated games, so the results presented here could be replicated with finite repetition in an appropriately modified version of the game.

The main finding of this paper is that when reputations can be established, that is, when the entrepreneur is sufficiently patient, then for-profit status is the optimal choice of organization form, and firms have an incentive to supply high quality services. In addition, it will be shown

\footnotetext{
${ }^{5}$ Licensing is an alternative means of controlling the quality of the service that is arguably imperfect because it sets only a minimum standard on the inputs used to provide the service and does not directly affect quality. For details on the impact of occupational licensing and certification on consumer welfare, see Shapiro (1986).

${ }^{6}$ See, for example, Klein and Leffler (1981), Shapiro (1983), Tirole (1988) and, more recently, Horner (2002).

${ }^{7} \mathrm{I}$ thank an anonymous referee for pointing this out.
} 
that there is an intermediate range for the discount factor of the entrepreneur where reputation for quality among those consumers valuing quality highly can be sustained only under nonprofit incorporation, as for such consumers the range of parameters under which high quality can be sustained in equilibrium is greater when the entrepreneur chooses nonprofit status. The intuition for these results follows a standard folk-theorem type of argument applied to the present setting: the loss of reputation associated with delivering bad quality service implies a substantial loss of future profits for the firm, and therefore when the entrepreneur is sufficiently forward-looking, then the fear of foregoing future profits disciplines him to deliver high quality services. The reason that for-profit status is preferable when the reputation mechanism works is that with repeated interaction, the for-profit firm can anticipate the future price reduction that will occur if it does not offer high quality and adjusts the optimal quality offered upwards relative to what it would offer in a one-off interaction. When this promise is credible, the consumer is willing to pay a higher price up-front and, therefore, removes the only advantage that nonprofit commitment conveyed to the entrepreneur in the one-shot game: the ability to charge a higher price. This suggests that in the context of the model, resorting to a reputation mechanism when this is feasible but maintaining a for-profit status is a less costly way for the entrepreneur to deliver high quality services than making the commitment to forego residual claims in profits.

We believe that without dismissing the contractual failure hypothesis, the repeated-interaction version of the model suggests that its explanatory power is perhaps more limited than previously thought. Furthermore, we argue in section five that the model can be useful in explaining some empirical evidence from the U.S. and Canada on the quality differences between commercial and nonprofit child care centres. Finally, we believe the paper has some normative implications, in particular, on the debate over the soundness of policies that favour nonprofit organizations on the grounds that commercial firms cannot be trusted to deliver high quality service because of their interest to earn profits. There may be a number of good reasons ${ }^{8}$ why governments should subsidize nonprofits, but our analysis suggests that, in many sectors, overcoming contractual failures may not be one of them.

The rest of the paper is organized as follows. The next section sets-up the basic one-period model of Glaeser and Shleifer, and section three extends it to a multi-period setting. The fourth section analyzes the optimal choice of firm status in the repeated game. Section five discusses the

\footnotetext{
${ }^{8}$ Among the social benefits of nonprofit provision of public services, one can single out the positive externalities associated with the acquisition of services such as education and childcare. Another important reason that a government may want to subsidize nonprofits is that they offer supplemental services to the ones that are publicly provided, which are tailored to the needs of consumers who are not satisfied with the quality of service that the government offers.
} 
predictions of the model and attempts to relate them to empirical evidence on the quality of child care centres across commercial and nonprofit providers in the U.S. and Canada. Finally, section six offers some concluding remarks.

\section{The One-Shot Game}

In order to set a benchmark as well as establish some notation we introduce here the basic setup of the one-period Glaeser-Shleifer model. The model analyzes the optimal choice of organization from the perspective of a rational entrepreneur who contemplates entering an industry and decides on firm type in order to maximize utility.

The timing of events is as follows. First, the entrepreneur sells one unit of the good to a competitive market of consumers at price $P$, which is paid up-front. Consumers are willing to pay $P_{e}=z-m\left(\widehat{q}-q_{e}\right)$ for one unit of the good of expected unverifiable quality $q_{e}$, where $\left(q_{e}=q_{f}\right.$ if the firm is for-profit and $q_{e}=q_{n}$ if nonprofit), $m$ is a parameter capturing the consumer's taste for unverifiable quality, and $z, \widehat{q}$ are constants. Then, the entrepreneur chooses what level of unverifiable quality $q$ to produce and delivers it. The total cost of producing one unit of quality $q$ is $c(q)$, where $c($.$) satisfies the standard regularity conditions: it is twice differentiable with c^{\prime}(q)>0$, $c^{\prime \prime}(q)>0, c(0)=0, c^{\prime}(0)=0, c^{\prime}(\infty)=\infty$. The key assumption is that while $q$ may be observable by the consumer, the final quality of the good cannot be verified by a third party, and therefore the transaction is subject to contractual incompleteness.

Before any transactions take place, the entrepreneur decides whether to organize the firm as for-profit or nonprofit, denoted by $f$ and $n$ respectively, in order to maximize utility. Specifically, entrepreneurs maximize a quasilinear utility function: $U_{i}=I-b\left(\widehat{q}-q_{i}\right), i \in\{f, n\}$ where $I$ is income, and $b$ is a parameter measuring entrepreneurs' altruistic preferences or intrinsic care for quality, which is independent of the firm's legal status. When the entrepreneur is for-profit, then income is equal to the profits the firm makes, while when he is nonprofit, he is subject to a nondistribution constraint, but a fraction $\delta, \delta<1$, of the profits can accrue to him in the form of benefits such as fewer work hours, better working conditions, and so on.

Entrepreneurs maximize utility by choosing quality $\left(q_{i}\right)$, while the price $P_{i}$ is predetermined by consumer's expectation of quality. Thus, if they choose for-profit status their objective is

$$
\max _{q_{f}} U_{f}=P_{f}-c\left(q_{f}\right)-b\left(\widehat{q}-q_{f}\right),
$$


while if they choose nonprofit status

$$
\max _{q_{n}} U_{n}=\delta\left(P_{n}-c\left(q_{n}\right)\right)-b\left(\widehat{q}-q_{n}\right)
$$

with $\delta<1$. The optimal quality level of a for-profit entrepreneur is given by $c^{\prime}\left(q_{f}^{s}\right)=b$, while a nonprofit entrepreneur chooses $c^{\prime}\left(q_{n}^{s}\right)=\frac{b}{\delta}$. As an immediate consequence of the convexity of $c($.$) ,$ it follows that $q_{n}^{s}>q_{f}^{s}$, a nonprofit entrepreneur commits to higher quality.

Hence, the entrepreneur chooses nonprofit status if $U_{n}>U_{f}$, or

$$
\delta\left(z-m\left(\widehat{q}-q_{n}^{s}\right)-c\left(q_{n}^{s}\right)\right)-b\left(\widehat{q}-q_{n}^{s}\right)>z-m\left(\widehat{q}-q_{f}^{s}\right)-c\left(q_{f}^{s}\right)-b\left(\widehat{q}-q_{f}^{s}\right) .
$$

This inequality implies that there exists a cut-off level of consumer taste for non-contractible quality $m^{*}$, with

$$
m^{*}=\frac{(1-\delta) z-\left(c\left(q_{f}^{s}\right)-\delta c\left(q_{n}^{s}\right)\right)-b\left(q_{n}^{s}-q_{f}^{s}\right)}{(1-\delta) \widehat{q}-q_{f}^{s}+\delta q_{n}^{s}}
$$

below which all entrepreneurs choose for-profit status and above which they all choose nonprofit status. ${ }^{9}$ Thus, the one-shot analysis of the game predicts that markets for services where unverifiable quality is not valued by consumers will be dominated by for-profit firms, while nonprofit firms will provide services whose unverifiable quality is important for consumers. ${ }^{10}$ In what follows we extend the static model to a multi-period setting where consumers and entrepreneurs interact repeatedly.

\footnotetext{
${ }^{9}$ Note that for $m>\bar{m}=\frac{\delta\left(z-c\left(q_{n}^{s}\right)\right)-b\left(\widehat{q}-q_{n}^{s}\right)}{\delta\left(\widehat{q}-q_{n}^{s}\right)}$, it is $U_{n}=0$, so the range of $m$ over which nonprofit status is preferable is bounded by $\bar{m}$. To rule out the degenerate case where nonprofit status is never optimal, we assume throughout that $m^{*}<\bar{m}$.

${ }^{10}$ Note that this prediction hinges on the assumption that consumers know whether the firm they are patronizing is for-profit or not-for-profit. If in fact consumers are unaware of the firm's type, they cannot form their expectations about quality based on it and, hence, trying to explain the emergence of nonprofit institutions as a response to contractual failures would be problematic.
} 


\section{The Repeated Game}

Now suppose that there is infinitely repeated interaction between the consumer and the entrepreneur. ${ }^{11}$ In the dynamic game, the consumer bases her purchasing decision on the firm's past behavior, that is, based on the firm's "reputation". If the firm has built a reputation for producing high quality, then the consumer will be willing to pay the associated price as long as the entrepreneur's past actions live up to his reputation. Thus, the entrepreneur can choose quality to maximize one-period utility, internalizing the adverse effect that his choice of quality has on the price that the consumer is willing to pay, namely, he can choose first-best quality. However, the entrepreneur's promise of high quality is credible provided it is incentive compatible for him to commit to providing better quality. That is, the entrepreneur will choose to build and maintain a reputation for high quality if this strategy generates a discounted stream of payoffs that exceed the one-shot gains of cheating and being punished in future transactions. As might be expected, if entrepreneurs are sufficiently patient, then the first-best outcome can be achieved under any ownership. ${ }^{12}$ In what follows we focus on (a) establishing and comparing the level of incentive compatible per-period payoffs that can be supported using punishment strategies that entail reversion to the outcome of the one-shot game under the two alternative organizational forms, and (b) on examining the possible configurations of firm status (for-profit, nonprofit) and quality (one-shot, reputation) that can occur in the infinite repetition of the stage game for the different values of the discount factor $\beta$ and the consumer taste for quality parameter $m$.

\subsection{For Profit Status}

In each period the structure of the interaction is as follows. The entrepreneur chooses organizational form, and the consumer pays up-front for the service. Then the entrepreneur makes his quality choice and delivers the service. The consumer observes the quality chosen by the entrepreneur and forms her beliefs about future quality. If the producer deviates from delivering promised quality he is punished in future interactions by the consumer agreeing to pay up-front only for one-shot quality. Notice that for this punishment to be possible, consumers ought to have a good idea about the quality chosen by the entrepreneur. This learning can be facilitated if consumers share

\footnotetext{
${ }^{11}$ The assumption that the firm is infinitely lived is important here. Behaviour that would be compatible with $\left(I C_{F}\right)$ cannot arise if there is a final period to the firm's life because the unique subgame Nash equilibrium of that game would be for the firm to cheat. Thus, backward induction rules out behaviour that satisfies $\left(I C_{F}\right)$ in a finitely repeated version of the game. In other words, $\left(I C_{F}\right)$ can only be satisfied if at any period $t$, there is a positive probability that the game will continue into period $t+1$.

${ }^{12}$ Note that as is typical in repeated games, this equilibrium is not unique. Here we focus on the one that maximizes the entrepreneur's payoff as being efficient and therefore plausibly focal.
} 
information, in which case punishment is meted out by future consumers. That is, the prospect of word of mouth information flows between consumers and the reactions that these may cause can also deter a firm from supplying a service of low quality. In the case of a chain of establishments, the reputation mechanism need not apply to a specific branch, but to the public image that the chain has developed for providing quality services. Also, information about quality can also be transmitted through other channels; for instance, it is not uncommon for providers to be required to publish record cards on their performance in sectors such as health care and education.

As a first step we must now determine the first-best level of quality and the resulting utility that can be sustained in the repeated game. Formally, each period the for-profit entrepreneur maximizes the following objective:

$$
\max _{q_{f}} U_{f}\left(q_{f}\right)=z-m\left(\widehat{q}-q_{f}\right)-c\left(q_{f}\right)-b\left(\widehat{q}-q_{f}\right)
$$

Therefore, the utility maximizing choice of quality $q_{f}^{*}(m)$, satisfies

$$
c^{\prime}\left(q_{f}^{*}(m)\right)=b+m \Rightarrow q_{f}^{*}(m)=c^{\prime-1}(b+m)^{13}
$$

and $\frac{d q_{f}^{*}(m)}{d m}=\frac{1}{c^{\prime \prime}\left(q_{f}^{*}(m)\right)}>0$. Moreover, per-period utility in this case is given by

$$
U_{f}\left(q_{f}^{*}(m)\right)=z-m\left(\widehat{q}-q_{f}^{*}(m)\right)-c\left(q_{f}^{*}(m)\right)-b\left(\widehat{q}-q_{f}^{*}(m)\right) .
$$

Note that the convexity of $c($.$) implies that q_{f}^{*}(m)>q_{f}^{s}$; that is, the entrepreneur has an incentive to increase the quality of the good relative to what he offers in the one-shot game (indeed, $q_{f}^{*}(m)$ maximizes total surplus) since he can extract all the surplus that is generated.

However, the first-best choice of quality $\left(q_{f}^{*}(m)\right)$ will be supported in equilibrium if and only if the discounted stream utility from adhering to honest behavior exceeds the payoff stream from the deviating path. That is, incentive compatibility for the for-profit entrepreneur writes as

$$
\left\{\begin{array}{lll}
\frac{1}{1-\beta} U_{f}\left(q_{f}^{*}(m)\right) \geq U_{f}^{c}(m)+\frac{\beta}{1-\beta} \quad U_{f}^{s}(m) & \text { if } \quad 0<m \leq m^{*} \\
\frac{1}{1-\beta} U_{f}\left(q_{f}^{*}(m)\right) \geq U_{f}^{c}(m)+\frac{\beta}{1-\beta} \quad U_{n}^{s}(m) & \text { if } \quad m^{*}<m \leq \bar{m}
\end{array}\right.
$$

where $\beta \in(0,1)$ is the discount factor and $U_{f}^{c}(m)=z-m\left(\widehat{q}-q_{f}^{*}(m)\right)-c\left(q_{f}^{s}\right)-b\left(\widehat{q}-q_{f}^{s}\right)$ is the utility the entrepreneur can attain if he deviates from offering the anticipated first-best level of quality and instead chooses the most profitable deviation, the one-shot utility maximizing choice of quality

\footnotetext{
${ }^{13} c^{\prime-1}($.$) is continuous and strictly increasing as a consequence of the continuity of c^{\prime}($.$) and that it is strictly$ increasing.
} 
$q_{f}^{s}$ (i.e. $q_{f}^{s}$ satisfies $c^{\prime}\left(q_{f}^{s}\right)=b$ ). Moreover, when the entrepreneur deviates he loses reputation, so in subsequent periods the consumer punishes him by reverting to the Nash equilibrium of the stage game. Given the strategy adopted by consumers, the entrepreneur's best-response after a deviation in which he cheated by providing one-shot level of quality is to continue providing low quality from then on. In particular, for $m$ higher than the cut-off level $m^{*}$, the entrepreneur chooses to come back as a nonprofit firm and make one-shot level of utility: $U_{n}^{s}(m)=\delta\left(z-m\left(\widehat{q}-q_{n}^{s}\right)-c\left(q_{n}^{s}\right)\right)-b\left(\widehat{q}-q_{n}^{s}\right)$ every period thereafter. If, instead, $m$ is less than $m^{*}$, then it is more profitable for the entrepreneur to maintain her for-profit legal status but is punished for having skimped on quality; therefore, his utility is reduced to the one-shot level of profit: $U_{f}^{s}(m)=z-m\left(\widehat{q}-q_{f}^{s}\right)-c\left(q_{f}^{s}\right)-b\left(\widehat{q}-q_{f}^{s}\right)$ every period after the deviation.

\section{$3.2 \quad$ Nonprofit Status}

If the entrepreneur is nonprofit, then his problem is to choose $q_{n}$ to maximize one-period utility $U_{n}\left(q_{n}\right)$ :

$$
\max _{q_{n}} U_{n}\left(q_{n}\right)=\delta\left(z-m\left(\widehat{q}-q_{n}\right)-c\left(q_{n}\right)\right)-b\left(\widehat{q}-q_{n}\right)
$$

The utility maximizing choice of quality $q_{n}^{*}(m)$ satisfies

$$
\delta c^{\prime}\left(q_{n}^{*}(m)\right)=b+\delta m \Rightarrow q_{n}^{*}(m)=c^{\prime-1}\left(\frac{b+\delta m}{\delta}\right)
$$

with $\frac{d q_{n}^{*}(m)}{d m}=\frac{1}{c^{\prime \prime}\left(q_{n}^{*}\right)}>0$, and $q_{n}^{*}(m)>q_{n}^{s}$. Utility is given by

$$
U_{n}\left(q_{n}^{*}(m)\right)=\delta\left(z-m\left(\widehat{q}-q_{n}^{*}(m)\right)-c\left(q_{n}^{*}(m)\right)\right)-b\left(\widehat{q}-q_{n}^{*}(m)\right)
$$

Notice that (6) and (10) imply that $q_{n}^{*}(m)>q_{f}^{*}(m)$; first-best quality under nonprofit status is greater than under for-profit status.

Lemma 1 There exists $\underline{m} \in\left(0, m^{*}\right)$, such that $U_{n}\left(q_{n}^{*}(m)\right)$ is $U_{f}^{s}(m)$ for $m \gtreqless \underline{m}$.

Proof. First we establish that $U_{f}^{s}(0)>U_{n}\left(q_{n}^{*}(0)\right)$. To see this, note that $U_{n}\left(q_{n}^{*}(0)\right)=\delta\left(z-c\left(q_{n}^{*}(0)\right)\right)-$ $b\left(\widehat{q}-q_{n}^{*}(0)\right)$, while $U_{f}^{s}(0)=z-c\left(q_{f}^{s}\right)-b\left(\widehat{q}-q_{f}^{s}\right)$, so $U_{f}^{s}(0)>U_{n}\left(q_{n}^{*}(0)\right)$ iff $z-c\left(q_{f}^{s}\right)-b\left(\widehat{q}-q_{f}^{s}\right)>$ $\delta\left(z-c\left(q_{n}^{*}(0)\right)\right)-b\left(\widehat{q}-q_{n}^{*}(0)\right) \Longleftrightarrow b q_{f}^{s}-c\left(q_{f}^{s}\right)+(1-\delta) z>b q_{n}^{*}(0)-c\left(q_{n}^{*}(0)\right)$. The last inequality is true because $b q_{f}^{s}-c\left(q_{f}^{s}\right)>b q_{n}^{*}(0)-c\left(q_{n}^{*}(0)\right)$ since $\left\{q_{f}^{s}=\underset{q}{\arg \max }[b q-c(q)]\right\}$. Also, 
$U_{n}\left(q_{n}^{*}\left(m^{*}\right)\right)>U_{f}^{s}\left(m^{*}\right)$. To see this, recall that $U_{f}^{s}\left(m^{*}\right)=U_{n}^{s}\left(m^{*}\right)$ and that $U_{n}\left(q_{n}^{*}(m)\right)>U_{n}^{s}(m) \forall$ $m \in[0, \bar{m}]$. Note that

$$
\frac{d U_{n}\left(q_{n}^{*}\left(m^{*}\right)\right)}{d m}=-\delta\left(\widehat{q}-q_{n}^{*}(m)\right)
$$

which implies that

$$
\frac{d U_{n}\left(q_{n}^{*}\left(m^{*}\right)\right)}{d m} \gtreqless 0 \Leftrightarrow q_{n}^{*}(m) \gtreqless \widehat{q}
$$

and that

$$
\frac{d^{2} U_{n}\left(q_{n}^{*}\left(m^{*}\right)\right)}{d m^{2}}=\delta \frac{d q_{n}^{*}(m)}{d m}>0
$$

that is, $U_{n}\left(q_{n}^{*}(m)\right)$ is continuous and U-shaped (it is decreasing, for $m$ such that $q_{n}^{*}(m)<\widehat{q}$, and increasing for $m$ such that $q_{n}^{*}(m)>\widehat{q}$ ) and $U_{f}^{s}(m)$ is continuous, strictly decreasing and linear for $m \in[0, \bar{m}]$. There exists a unique $\underline{m} \in\left(0, m^{*}\right)$ such that $U_{n}\left(q_{n}^{*}(\underline{m})\right)=U_{f}^{s}(\underline{m})$, and therefore $U_{n}\left(q_{n}^{*}(m)\right)$ is $\gtreqless U_{f}^{s}(m)$ for $m \gtreqless \underline{m}$.

Lemma 1 suggests that for low $m, m \in(0, \bar{m})$, nonprofit status is not desirable even if a reputation for quality can be established. The intuition is that when $m$ is small, the price premium that the consumer is willing to pay a nonprofit firm for higher quality is not enough to compensate the entrepreneur for the loss of income due to the limited access to profits.

As in the case of a for-profit entrepreneur, the first-best choice of quality $\left(q_{n}^{*}(m)\right)$ will be supported in equilibrium if and only if the discounted stream of utility from adhering to honest behavior exceeds the payoff stream from the deviating path. That is, incentive compatibility for a nonprofit entrepreneur is

$$
\left\{\begin{array}{ll}
\frac{1}{1-\beta} U_{n}\left(q_{n}^{*}\left(m^{*}\right)\right) \geq U_{n}^{c}(m)+\frac{\beta}{1-\beta} \quad U_{f}^{s}(m) & \text { if } \quad \underline{m}<m<m^{*} \\
\frac{1}{1-\beta} U_{n}\left(q_{n}^{*}\left(m^{*}\right)\right) \geq U_{n}^{c}(m)+\frac{\beta}{1-\beta} \quad U_{n}^{s}(m) & \text { if } \quad m^{*} \leq m \leq \bar{m}
\end{array} \quad\left(I C_{N}\right)\right.
$$

where $U_{n}^{c}(m)=\delta\left(z-m\left(\widehat{q}-q_{n}^{*}(m)\right)-c\left(q_{n}^{s}\right)\right)-b\left(\widehat{q}-q_{n}^{s}\right)$ is the utility the entrepreneur can attain if he deviates from offering the anticipated first-best level of quality and instead produces the one-shot utility maximizing choice of quality $q_{n}^{s}$ (i.e. $q_{n}^{s}$ satisfies $\delta c^{\prime}\left(q_{n}^{s}\right)=b$ ). The arguments regarding the choice of legal status and the corresponding payoff after the deviation are analogous to the ones we made above for the for-profit case. The difference here is that, as Lemma 1 suggests, for $m<m$, it is $U_{f}^{s}(m)>U_{n}\left(q_{n}^{*}\left(m^{*}\right)\right)$, so $\left(I C_{N}\right)$ cannot be satisfied, which implies that a nonprofit entrepreneur cannot commit to providing first-best quality $\left(q_{n}^{*}(m)\right)$ to the low $m$ segment of the market. 


\section{Optimal Choice of Organizational Form}

\subsection{Overview}

In the multi-period formulation, the entrepreneur has two distinct decisions to make: what organizational type to choose and whether to establish reputation for quality or not. Consequently, four possible combinations of firm-status (for-profit, nonprofit) and quality (first-best, one-shot) may arise. The optimal choice of firm status and quality can be analyzed with reference to the two critical exogenous parameters: the firm's discount factor $\beta$ and consumer's sensitivity to unverifiable quality $m$. To this end, it is useful to rearrange $\left(I C_{F}\right)$ and $\left(I C_{N}\right)$ as follows:

$$
\begin{gathered}
\left\{\begin{array}{lll}
\beta \geq \frac{U_{f}^{c}(m)-U_{f}\left(q_{f}^{*}(m)\right)}{U_{f}^{c}(m)-U_{f}^{s}(m)} & \text { if } & 0<m \leq m^{*} \\
\beta \geq \frac{U_{f}^{c}(m)-U_{f}\left(q_{f}^{*}(m)\right)}{U_{f}^{c}(m)-U_{n}^{s}(m)} & \text { if } & m^{*}<m \leq \bar{m}
\end{array}\right. \\
\left\{\begin{array}{lll}
\beta \geq \frac{U_{n}^{c}(m)-U_{n}\left(q_{n}^{*}(m)\right)}{U_{n}^{c}(m)-U_{f}^{s}(m)} & \text { if } & \underline{m}<m<m^{*} \\
\beta \geq \frac{U_{n}^{c}(m)-U_{n}\left(q_{n}^{*}(m)\right)}{U_{n}^{c}(m)-U_{n}^{s}(m)} & \text { if } & m^{*} \leq m \leq \bar{m}
\end{array}\right.
\end{gathered}
$$

The right-hand-side of (13) and (14) define critical values for the discount factor $\beta$, which we

shall denote $\beta_{f}(m)$ and $\beta_{n}(m)$, respectively, above which delivery of first-best quality can be sustained. That is, for $m$ such that $\beta>\beta_{f}(m),\left(I C_{F}\right)$ is satisfied and the for-profit entrepreneur delivers first-best quality $q_{f}^{*}(m)$. Likewise, for $m$ such that $\beta>\beta_{n}(m),\left(I C_{N}\right)$ is satisfied and the nonprofit entrepreneur chooses the first-best level quality $q_{n}^{*}(m)$. Our aim is to establish, first, which organizational form is preferable when reputations can be established, and second, which organizational form can support first best quality for the widest range of discount factors; namely, we shall be interested in comparing $\beta_{f}(m)$ to $\beta_{n}(m)$.

To compare utility across organizational forms, note that the relative benefit of being for-profit when $\left(I C_{F}\right)$ and $\left(I C_{N}\right)$ are slack is given by

$$
G(m)=\left[(m+b) q_{f}^{*}(m)-c\left(q_{f}^{*}(m)\right)\right]-\left[(\delta m+b) q_{n}^{*}(m)-\delta c\left(q_{f}^{*}(m)\right)\right]+(1-\delta)(z-m \widehat{q})
$$

The following lemma applies:

Lemma 2 When the entrepreneur can commit to the first-best level of quality $q_{f}^{*}(m)$ and $q_{n}^{*}(m)$, 
then for-profit status is more attractive at any level of $m$, that is, $G(m)>0 \forall m \in(0, \bar{m}) .{ }^{14}$

Proof. We want to show that $U_{f}\left(q_{f}^{*}(m)\right)>U_{n}\left(q_{n}^{*}(m)\right)$, or equivalently that

$$
z-m\left(\widehat{q}-q_{f}^{*}(m)\right)-c\left(q_{f}^{*}(m)\right)-b\left(\widehat{q}-q_{f}^{*}(m)\right)>\delta\left(z-m\left(\widehat{q}-q_{n}^{*}(m)\right)-c\left(q_{n}^{*}(m)\right)\right)-b\left(\widehat{q}-q_{n}^{*}(m)\right) .
$$

To show that (16) holds note that

$$
z-m\left(\widehat{q}-q_{f}^{*}(m)\right)-c\left(q_{f}^{*}(m)\right)-b\left(\widehat{q}-q_{f}^{*}(m)\right)>z-m\left(\widehat{q}-q_{n}^{*}(m)\right)-c\left(q_{n}^{*}(m)\right)-b\left(\widehat{q}-q_{n}^{*}(m)\right),
$$

since

$$
q_{f}^{*}(m)=\underset{q}{\arg \max }[(b+m) q-c(q)]
$$

which implies that

$z-m\left(\widehat{q}-q_{f}^{*}(m)\right)-c\left(q_{f}^{*}(m)\right)-b\left(\widehat{q}-q_{f}^{*}(m)\right)>\delta\left(z-m\left(\widehat{q}-q_{n}^{*}(m)\right)-c\left(q_{n}^{*}(m)\right)\right)-b\left(\widehat{q}-q_{n}^{*}(m)\right.$ for $\delta \in(0,1)$

which establishes (16).

This result suggests that reputation forces favour for-profit status. The intuition for this is that as $m$ increases, the for-profit firm can now anticipate the price reduction that will occur if it does not offer better quality and adjusts the optimal quality offered $q_{f}^{*}(m)$ upwards, thus remaining more attractive than the nonprofit firm for any $m$. This is the power of the reputation mechanism; it allows for-profit firms to commit credibly to delivering the high quality service because it is more valuable to them to do so.

Next, in order to compare $\beta_{f}(m)$ to $\beta_{n}(m)$, notice that, after substitution and the appropriate simplifications, (13) and (14) imply that

$$
\beta_{f}(m)=\left\{\begin{array}{ccc}
\frac{\left(b q_{f}^{s}-c\left(q_{f}^{s}\right)\right)-\left(b q_{f}^{*}(m)-c\left(q_{f}^{*}(m)\right)\right)}{m\left(q_{f}^{*}(m)-q_{f}^{s}\right)} & \text { if } \quad 0<m \leq m^{*} \\
\frac{\left(b q_{f}^{s}-c\left(q_{f}^{s}\right)\right)-\left(b q_{f}^{*}(m)-c\left(q_{f}^{*}(m)\right)\right)}{(1-\delta)(z-m \widehat{q})+m q_{f}^{*}(m)-c\left(q_{f}^{s}\right)+b q_{f}^{s}-\delta m q_{n}^{s}+\delta c\left(q_{n}^{s}\right)-b q_{n}^{s}} & \text { if } & m^{*}<m \leq \bar{m}
\end{array}\right.
$$

and

$$
\beta_{n}(m)=\left\{\begin{array}{ccc}
\frac{\left(b q_{n}^{s}-\delta c\left(q_{n}^{s}\right)\right)-\left(b q_{n}^{*}(m)-\delta c\left(q_{n}^{*}(m)\right)\right)}{-(1-\delta)(z-m \widetilde{q})+\delta m q_{n}^{*}(m)-\delta c\left(q_{n}^{s}\right)+b q_{n}^{s}-m q_{f}^{s}+c\left(q_{f}^{s}\right)-b q_{f}^{s}} & \text { if } \quad \underline{m}<m<m^{*} \\
\frac{\left(b q_{n}^{s}-\delta c\left(q_{n}^{s}\right)\right)-\left(b q_{n}^{*}(m)-\delta c\left(q_{n}^{*}(m)\right)\right)}{\delta m\left(q_{n}^{*}(m)-q_{n}^{s}\right)} & \text { if } \quad m^{*} \leq m \leq \bar{m}
\end{array} .\right.
$$

\footnotetext{
${ }^{14}$ It follows, a fortiori, that for profit status is more attractive when the entrepreneur can choose first-best quality $q_{f}^{*}(m)$ when for-profit, but $\left(I C_{N}\right)$ is not satisfied. That is, $U_{f}\left(q_{f}^{*}(m)\right)>U_{n}\left(q_{n}^{*}(m)\right)$ implies that $U_{f}\left(q_{f}^{*}(m)\right)>U_{n}^{s}(m)$ $\forall m \in(0, \bar{m})$.
} 
Analyzing the monotonicity and the relative position of $\beta_{f}(m)$ and $\beta_{n}(m)$ generally, as inspection of (17) and (18) suggests, is intractable. To gain some intuition for this, notice that $\beta_{f}(m)$ and $\beta_{n}(m)$ can be rewritten as follows:

$$
\beta_{i}(m)=\frac{B_{i}(m)}{B_{i}(m)+L_{i}(m)} \text { for each } i \in\{f, n\}
$$

where $B_{i}(m)=U_{i}^{c}(m)-U_{i}\left(q_{i}^{*}(m)\right)$ denotes the one-time benefit from cheating, and $L_{i}(m)=$ $U_{i}\left(q_{i}^{*}(m)\right)-U_{i}^{s}(m)$ denotes the absolute value of the future loss induced by the punishment. From (19), it follows that

$$
\beta_{f}(m) \gtreqless \beta_{n}(m) \Leftrightarrow \frac{B_{f}(m)}{L_{f}(m)} \gtreqless \frac{B_{n}(m)}{L_{n}(m)} .
$$

This last condition suggests that comparing $\beta_{f}(m)$ to $\beta_{n}(m)$ amounts to comparing the ratio of benefits and losses associated with a deviation across organizational forms and for different values of $m$. Intuitively, one might think that under nonprofit status the manager's incentive to cheat is attenuated because he can only partially enjoy the extra profits generated due to cheating, so we might expect $B_{n}(m)$ to be smaller than $B_{f}(m)$. On the other hand, though, the value of the punishment inflicted in the event of cheating is also smaller (the expression in the denominator), so it is not immediately clear how $\beta_{f}(m)$ compares to $\beta_{n}(m)$.

In particular, closer inspection of (17) and (18) suggests that the value and the monotonicity of these expressions depend on relative changes of terms involving $c($.$) , which renders the problem$ intractable. Therefore, in order to proceed to a full characterization of the properties of $\beta_{f}(m)$ and $\beta_{n}(m)$ and therefore of the optimal choice of firm, we need to place some structure on the cost function $c(q)$.

Assumption $1 c(q)=\frac{1}{2} q^{2} \cdot{ }^{15}$

The following lemma describes the properties of $\beta_{f}(m)$ and $\beta_{n}(m)$.

Lemma 3 (i) $\beta_{f}(m)=\frac{1}{2}$ for $m \in\left(0, m^{*}\right]$, and $\beta_{n}(m)=\frac{1}{2}$ for $m \in\left[m^{*}, \bar{m}\right)$.

(ii) $\beta_{n}(m)>\beta_{f}(m)$ for $m \in\left(0, m^{*}\right)$, and $\beta_{f}(m)>\beta_{n}(m)$ for $m \in\left(m^{*}, \bar{m}\right)$.

(iii) $\beta_{n}(m)$ is decreasing, for $m \in\left(0, m^{*}\right)$.

\footnotetext{
${ }^{15}$ Note that this specification satisfies the regularity conditions imposed on $c($.$) . This particular formulation is$ convenient for deriving insights from the analytic results that follow.
} 
(iv) $\beta_{f}(m)$ reaches a maximum at $m=2 m^{*}$.

Proof. First note that when $c(q)=\frac{1}{2} q^{2}$, the marginal cost is $c^{\prime}(q)=q$, which implies that $q_{f}^{s}=b$ and $q_{n}^{s}=\frac{1}{\delta} b$, while $c\left(q_{f}^{s}\right)=\frac{1}{2} b^{2}$ and $c\left(q_{n}^{s}\right)=\frac{1}{2}\left(\frac{1}{\delta} b\right)^{2}$. Also, substitution into (6) and (10) implies that $q_{f}^{*}(m)=b+m$ and $q_{n}^{*}(m)=\frac{1}{\delta}(b+\delta m)$, so $c\left(q_{f}^{*}(m)\right)=\frac{1}{2}(b+m)^{2}$ and $c\left(q_{n}^{*}(m)\right)=\frac{1}{2}\left(\frac{1}{\delta}(b+\delta m)\right)^{2}$.

We show part (i) by inserting the values for $q_{f}^{s}, q_{n}^{s}, c\left(q_{f}^{s}\right), c\left(q_{n}^{s}\right), q_{f}^{*}(m), q_{n}^{*}(m), c\left(q_{f}^{*}(m)\right)$, and $c\left(q_{n}^{*}(m)\right)$ into (17) and (18), and simplifying to obtain

$$
\beta_{f}(m)=\left\{\begin{array}{cc}
\frac{1}{2} & \text { if } \quad 0<m \leq m^{*} \\
\frac{m^{2} / 2}{(1-\delta)\left(z-\frac{b^{2}}{2 \delta}-\widehat{q} m\right)+m^{2}} & \text { if } \quad m^{*}<m \leq \bar{m}
\end{array}\right.
$$

and

$$
\beta_{n}(m)=\left\{\begin{array}{cc}
\frac{\delta m^{2} / 2}{-(1-\delta)\left(z-\frac{b^{2}}{2 \delta}-\widehat{q} m\right)+\delta m^{2}} & \text { if } \quad \underline{m}<m<m^{*} \\
\frac{1}{2} & \text { if } \quad m^{*} \leq m \leq \bar{m}
\end{array},\right.
$$

which establishes part (i) of the lemma.

For part (ii), it is useful to compute $m^{*}$ first. From (4), we have

$$
m^{*}=\frac{(1-\delta) z-\left(c\left(q_{f}^{s}\right)-\delta c\left(q_{n}^{s}\right)\right)-b\left(q_{n}^{s}-q_{f}^{s}\right)}{(1-\delta) \widehat{q}-q_{f}^{s}+\delta q_{n}^{s}}=\frac{(1-\delta) z-\left(\frac{1}{2} b^{2}-\delta \frac{1}{2}\left(\frac{1}{\delta} b\right)^{2}\right)-b\left(\frac{1}{\delta} b-b\right)}{(1-\delta) \widehat{q}-b+\delta \frac{1}{\delta} b}=\frac{z-\frac{b^{2}}{2 \delta}}{\widehat{q}}
$$

We need to show that first, for $m \in\left(0, m^{*}\right), \beta_{n}(m)>\beta_{f}(m)$, or equivalently that

$$
\frac{\delta m^{2} / 2}{-(1-\delta)\left(z-\frac{b^{2}}{2 \delta}-\widehat{q} m\right)+\delta m^{2}}>\frac{1}{2} \Leftrightarrow m<\frac{z-\frac{b^{2}}{2 \delta}}{\widehat{q}}=m^{*}
$$

so the inequality holds. Second, we want to show that for $m \in\left(m^{*}, \bar{m}\right), \beta_{f}(m)>\beta_{n}(m)$, or equivalently that

$$
\frac{1}{2}<\frac{m^{2} / 2}{(1-\delta)\left(z-\frac{b^{2}}{2 \delta}-\widehat{q} m\right)+m^{2}} \Leftrightarrow m>\frac{z-\frac{b^{2}}{2 \delta}}{\widehat{q}}=m^{*},
$$

so the second inequality is also established.

For part (iii), differentiating $\beta_{n}(m)$ with respect to $m$ yields 


$$
\frac{\partial \beta_{n}(m)}{\partial m}=\frac{\delta m\left[-(1-\delta)\left(z-\frac{b^{2}}{2 \delta}-\widehat{q} m\right)+\delta m^{2}\right]-\frac{1}{2} \delta m^{2}(2 \delta m+\widehat{q}(1-\delta))}{\left[-(1-\delta)\left(z-\frac{b^{2}}{2 \delta}-\widehat{q} m\right)+\delta m^{2}\right]^{2}}
$$

implying that

$$
\begin{aligned}
\frac{\partial \beta_{n}(m)}{\partial m} & \lesseqgtr 0 \Leftrightarrow \delta m\left[-(1-\delta)\left(z-\frac{b^{2}}{2 \delta}-\widehat{q} m\right)+\delta m^{2}\right]-\frac{1}{2} \delta m^{2}(2 \delta m+\widehat{q}(1-\delta)) \lesseqgtr 0 \\
& \Leftrightarrow m \lesseqgtr 2 \frac{z-\frac{b^{2}}{2 \delta}}{\widehat{q}}=2 m^{*}
\end{aligned}
$$

so for $m \in\left(0, m^{*}\right), \frac{\partial \beta_{n}(m)}{\partial m}<0$, that is, $\beta_{n}(m)$ is decreasing.

For part (iv), differentiating $\beta_{f}(m)$ with respect to $m$,

$$
\frac{\partial \beta_{f}(m)}{\partial m}=\frac{m\left[(1-\delta)\left(z-\frac{b^{2}}{2 \delta}-\widehat{q} m\right)+m^{2}\right]-\frac{1}{2} m^{2}(2 m-\widehat{q}(1-\delta))}{\left[(1-\delta)\left(z-\frac{b^{2}}{2 \delta}-\widehat{q} m\right)+m^{2}\right]^{2}}
$$

implying that

$$
\begin{aligned}
\frac{\partial \beta_{f}(m)}{\partial m} & \lesseqgtr 0 \Leftrightarrow m\left[(1-\delta)\left(z-\frac{b^{2}}{2 \delta}-\widehat{q} m\right)+m^{2}\right]-\frac{1}{2} m^{2}(2 \delta m+\widehat{q}(1-\delta)) \lesseqgtr 0 \\
& \Leftrightarrow m \lesseqgtr 2\left(\frac{z-\frac{b^{2}}{2 \delta}}{\widehat{q}}\right)=2 m^{*},
\end{aligned}
$$

so $\beta_{f}(m)$ is flat in $\left(0, m^{*}\right)$, increasing in $\left(m^{*}, 2 m^{*}\right)$, and decreasing in $\left(2 m^{*}, \bar{m}\right)$, which implies that it reaches a maximum at $2 m^{*}$.

The analysis is significantly aided by reference to Figure 1, which Lemma 3 helps us construct and which illustrates $\beta_{f}(m)$ and $\beta_{n}(m)$ in $(m, \beta)$ space. ${ }^{16}$ Note that for $m$ such that the punishment path after cheating does not include conversion of legal status, $\beta_{f}(m)$ and $\beta_{n}(m)$ remain flat and equal. This, however, is not true in the subintervals of $(\underline{m}, \bar{m})$ where the punishment phase entails change of the firm's legal status prescribed by entrepreneur's optimal behavior in the one-shot game. In this case, two opposite effects govern the monotonicity of $\beta_{f}(m)$ and $\beta_{n}(m)$. On one hand, the first period benefit of cheating increases with $m$, which implies that incentive compatibility becomes stricter. On the other hand, the benefit of committing to high quality, relative to being a one-shot firm, increases with $m$ for periods two onwards as the reputation firm adjusts optimal quality upwards while the one-shot firm adheres to the stage game quality. For $m \in\left(0, m^{*}\right]$, the second

\footnotetext{
${ }^{16}$ The figure is constructed assuming the following parameter values: $\delta=0.5, Z=50, b=1, \widehat{q}=3$.
} 
effect dominates the first effect we described above, so the overall tendency is for $\left(I C_{N}\right)$ to become increasingly easier to satisfy; hence $\beta_{n}(m)$ is decreasing. For $m \in\left(m^{*}, \bar{m}\right), \beta_{f}(m)$ is non-monotonic because initially the first effect dominates while for higher $m$ the second effect takes over.

\section{[Figure 1]}

We can now determine the entrepreneur's choice of firm status for $\beta$ lying in three different subintervals of $(0,1)$ by referring to figure 1 .

\subsection{Optimal choice when $\beta \in\left[\beta_{f}\left(2 m^{*}\right), 1\right)$}

The following proposition applies:

Proposition 1 If the entrepreneur is sufficiently patient (i.e. $\beta \geq \beta_{f}\left(2 m^{*}\right)$ ), then the $\left(I C_{F}\right)$ never binds and for-profit status is the preferred choice of organization, for any level of $m$. Furthermore, the first-best level of quality $\left(q_{f}^{*}(m)\right)$ can be sustained.

Proof. Follows directly from Lemma 2 and the fact that $\beta_{f}\left(2 m^{*}\right)$ is the maximum value that $\beta_{f}(m)$ takes in $(0, \bar{m})$. Therefore, for $\beta \geq \beta_{f}\left(2 m^{*}\right),\left(I C_{F}\right)$ is always satisfied, so it follows from Lemma 2 that for-profit status is the optimal choice of legal status and that first best quality $\left(q_{f}^{*}(m)\right)$ is provided.

\subsection{Optimal choice when $\beta \in\left(\frac{1}{2}, \beta_{f}\left(2 m^{*}\right)\right)$}

To analyze the optimal choice of organizational form when $\beta$ lies in the interval $\left(\frac{1}{2}, \beta_{f}\left(2 m^{*}\right)\right)$, it is useful to divide the relevant $(\beta, m)$ space into the following two mutually exclusive and exhaustive regions, also illustrated in Figure 2:

Definition 1 a) Region $A$ consists of $\beta \in\left[\beta_{f}(m), \beta_{f}\left(2 m^{*}\right)\right)$ and $m \in(0, \bar{m})$ such that $\beta>\beta_{f}(m)$.

b) Region $B$ consists of $\beta \in\left(\frac{1}{2}, \beta_{f}(m)\right)$ and $m \in\left(m^{*}, \bar{m}\right)$ such that $\beta_{n}(m)<\beta_{f}(m)$.

The following proposition summarizes the optimal choice of organizational form and quality for $\beta \in\left(\frac{1}{2}, \beta_{f}\left(2 m^{*}\right)\right):$ 
Proposition 2 a) In Region A the entrepreneur chooses for-profit status and delivers first-best quality $q_{f}^{*}(m)$.

b) In Region $B$ the entrepreneur chooses nonprofit status and delivers first-best quality $q_{n}^{*}(m)$.

Proof. a) Note that in region $A$ it is $\beta>\beta_{f}(m)$, so $\left(I C_{F}\right)$ is satisfied; thus it follows from Lemma 2 that for-profit status is the optimal choice of legal status and that first best quality $\left(q_{f}^{*}(m)\right)$ is provided.

b) In region $B$ it is $\beta_{n}(m)<\beta<\beta_{f}(m)$, implying that only $\left(I C_{N}\right)$ is satisfied, which means that nonprofit status offering first best quality $\left(q_{n}^{*}(m)\right)$ will be chosen.

Moreover, whether $\left(I C_{F}\right)$ is satisfied or not, for $m \in\left(m^{*}, \bar{m}\right)$ depends on parameters such as the consumer's willingness to pay for the service $(z)$ and the entrepreneur's altruistic taste $b$.

Remark 1 Differentiation of $\beta_{f}(m)$ for $m \in\left(m^{*}, \bar{m}\right)$ yields
a) $\frac{\partial \beta_{f}(m)}{\partial z}<0$,
b) $\frac{\partial \beta_{f}(m)}{\partial b}>0$.

Thus, the higher the profitability of the industry or the firm, the larger area $A$ becomes, which implies that the greater is the likelihood that $\left(I C_{F}\right)$ will be satisfied and entrepreneurs are going to choose for-profit status as the preferred form of organization. On the other hand, the more an entrepreneur is intrinsically concerned about quality, the larger area $B$ becomes, which means that it is harder to maintain first-best quality under for-profit status.

\subsection{Optimal choice when $\beta \in\left(0, \frac{1}{2}\right)$}

The following proposition applies:

Proposition 3 If $\beta<\frac{1}{2}$, then $\left(I C_{F}\right)$ and $\left(I C_{N}\right)$ are never satisfied for any level of $m$ and reputations cannot be sustained regardless of what legal status the entrepreneur chooses. The optimal choice of organizational type is the one described in the one-shot game.

Proof. It is immediately clear from Lemma 3 and figure 1 that for $\beta<\frac{1}{2}, \beta<\beta_{f}(m)$ and $\beta<\beta_{n}(m)$, so both $\left(I C_{F}\right)$ and $\left(I C_{N}\right)$ fail. 
For reference, the various possible outcomes of the repeated game are also illustrated in Figure 2 and summarized in Table 1.

[Figure 2]

Table 1

Summary of Optimal Choice of Firm Status and Quality by Region

\begin{tabular}{ccc}
\hline \hline Region & Firm Status & Quality \\
\hline$(0, \bar{m}) \times\left[\beta_{f}\left(2 m^{*}\right), 1\right)$ & $F P$ & $q_{f}^{*}$ \\
$A:(0, \bar{m}) \times\left(\beta_{f}(m), \beta_{f}\left(2 m^{*}\right)\right)$ & $F P$ & $q_{f}^{*}$ \\
$B:\left(m^{*}, \bar{m}\right) \times\left(\frac{1}{2}, \beta_{f}(m)\right)$ & $N F P$ & $q_{n}^{*}$ \\
$(0, \bar{m}) \times\left(0, \frac{1}{2}\right)$ & One-Shot Analysis \\
\hline \hline
\end{tabular}

The foregoing analysis suggests that if we imagine that there is a distribution of $\beta^{\prime} s$ in the population of entrepreneurs, then those who have sufficiently high $\beta$ will choose for-profit status and will deliver high quality service. There is an intermediate range of $\beta^{\prime} s$ where the choice of firm status varies with $m$. Finally, for very low $\beta$, reputations are not going to be established and the one-shot analysis of Glaeser and Shleifer will apply. ${ }^{17}$ The value of $\beta$ need not be interpreted literally as a discount factor. There are plenty of reasons that one would expect variation in managerial outlook of future profitability that are not directly related to one's personal rate of time preference. For example, some markets may have higher demand growth than others, which means that the potential future losses from shirking on quality and losing reputation in these markets are higher. These kinds of differences in market-specific or sector-specific conditions can be regarded as determinants of the effective discount factors that have to be applied by potential entrants when deciding which firm status to choose and what level of quality to offer.

It is noteworthy that if we were to adopt the view that the optimal organizational form is the one that minimizes the discount factor that is necessary to sustain first-best quality, then the outcome of the repeated game matches with that of the static game. That is, there exists a threshold value for consumer preference for quality $m^{*}$, above which nonprofit status is optimal and below which for-profit status dominates. This way of ranking organizations may be relevant if, for instance, we believe that free-entry competition among firms will ensure that the incentive compatible constraints $\left(I C_{F}\right)$ and $\left(I C_{N}\right)$ bind. Then, we should expect the organizational form with the lower critical value for the discount factor to drive the other one out of the market.

\footnotetext{
${ }^{17}$ There may also be ideological or religious motivations that make nonprofit status attractive for some people and therefore affect the supply of nonprofit activity. Much like most of the literature that relies on contractual failures, we have abstracted from these considerations here.
} 
The analysis of the optimal choice of firm status was considerably simplified by introducing an explicit functional form for the cost function since a general characterization is not possible. The particular formulation we used is convenient for deriving simple analytical results, but numerical examples using higher-order power functions and the exponential function suggest that the insights obtained are robust to alternative specifications of the cost function. Table 2 reports the three critical cut-off values of $m$ obtained from these examples, supposing that $\delta=0.5, Z=50, b=$ $1, \widehat{q}=3$. Note that $\widetilde{m}$ denotes the threshold level of $m$ below which $\beta_{f}(m)<\beta_{n}(m)$ and above which $\beta_{f}(m)>\beta_{n}(m)$. One can see in Table 2 that the basic properties of $\beta_{f}(m)$ and $\beta_{n}(m)$ and therefore the pattern of the optimal choice of organizational form that emerge from Table 1 are present in all of the alternative specifications of the cost function we consider.

Table 2: Numerical Examples

\begin{tabular}{lccc}
\hline \hline Cost function & $m^{*}$ & $\tilde{m}$ & $\bar{m}$ \\
\hline$c(q)=\frac{1}{2} q^{2}$ & 16.33 & 16.33 & 46.00 \\
$c(q)=\frac{1}{3} q^{3}$ & 20.48 & 23.72 & 28.93 \\
$c(q)=\frac{1}{4} q^{4}$ & 21.95 & 24.66 & 26.37 \\
$c(q)=\frac{1}{5} q^{5}$ & 22.70 & 24.89 & 25.35 \\
$c(q)=\left(e^{q}-1\right)$ & 13.43 & 16.51 & 19.24 \\
\hline \hline
\end{tabular}

Rest of parameter values: $\delta=0.5, Z=50, b=1, \widehat{q}=3$.

\section{$5 \quad$ Relating the Model to some Empirical Evidence}

We believe that the predictions obtained from the dynamic framework can help us to understand some facts concerning quality differentials in mixed sectors which the one-shot model falls short of explaining. For instance, consider the market for child care, which features a considerable nonprofit presence, making it appropriate for drawing comparisons between the quality offered by for-profit and nonprofit providers. ${ }^{18}$ Furthermore, the quality dimension in child care is arguably hard to measure and verify, which makes it amenable to the incomplete contracts framework we have laid out above. Our reading of the empirical evidence on the between-sector differences in quality from the U.S. and Canada ${ }^{19}$ is that although most studies find that nonprofit centres as a group obtain higher

\footnotetext{
${ }^{18}$ Studies that examine the relative performance of nonprofits are too many to list here; see Rose-Ackerman (1996) for a comprehensive review of the literature. Ortmann and Schlesinger (2003) review the empirical work on ownershiprelated differences in quality from various mixed industries.

${ }^{19}$ For evidence from the U.S. child care sector, see the survey by Blau and Currie (2006) and the references therein. For evidence from Canada, see Krashinsky (1998) and Doherty et al. (2002).
} 
scores on observational measures of overall quality developed by child development experts ${ }^{20}$ this finding cannot be interpreted as a direct confirmation of the contractual failure theory. First, the differences on average quality between the two groups are not overwhelming, and there is variation in quality within each category of auspice. That is, there are commercial centres that offer high quality and nonprofit centres that offer low quality. This possibility though is in contradiction with the strong form of the contractual failure view of the world which predicts that only nonprofits will occupy the upper part of the quality distribution. Second, it seems very likely that the greater access to government funding and subsidies nonprofits enjoy in certain jurisdictions could at least partly account for the reported difference in average quality between the nonprofit and commercial child care sectors. Finally, it is possible that the variation in quality may simply reflect choice of market niche and be unrelated to informational asymmetries of any sort. For example, for-profit child care centres may choose to substitute lower quality care for more convenient arrangements offered to the parents (convenient location, longer hours, etc.).

Yet another explanation of the apparent between-sector quality differential, and indeed one that the analysis of the repeated version of the model points to, is that because for-profit status dominates the lower part of the quality distribution $\left(m<m^{*}\right)$, even though there are some high quality for-profit centres (in area $A$ and for $\beta \in\left[\beta_{f}\left(2 m^{*}\right), 1\right)$ ), on average the quality provided by the commercial sector is lower than the nonprofit which has a higher quality threshold. ${ }^{21}$ Note that this explanation relies on the implicit assumption that there is exogenous heterogeneity in the discount factor in the population of entrepreneurs. Furthermore, in markets where nonprofits have lower costs $(c(q))$ because of access to free space and utilities, the model suggests that more entrepreneurs will choose nonprofit status, which would increase the average quality care in the nonprofit sector and lower it in the commercial sector.

In light of this interpretation of the quality differential, it is interesting to revisit the ongoing debate over the effectiveness of subsidy policies that discriminate against for-profit child care centres on the basis that they are untrustworthy to provide high quality care. We argued above that the existing empirical evidence on the impact of centre ownership on care quality is scant and does not allow for sweeping conclusions, while the model considered here demonstrates that reputations can provide enough incentives for profit-maximizing entrepreneurs to offer high quality services when the playing field is levelled. Perhaps future empirical work may be able to settle the debate by identifying the extent to which quality differences between sectors echo contractual failures or

\footnotetext{
${ }^{20} \mathrm{It}$ is important that these instruments of child care quality refer to non-contractible quality and are distinct from structural measures of quality, such as the child-teacher ratio, which are contractible.

${ }^{21}$ Recall that nonprofit status is chosen only for $m>m^{*}$.
} 
unequal funding opportunities.

\section{Conclusion}

The idea that nonprofit organizations can solve market imperfections attributable to asymmetric information between consumers and producers regarding hard to verify quality of certain services has been a particularly influential explanation of the emergence and expansion of the nonprofit sector. Our task in this paper has been to perform a robustness check of this theory by allowing reputations to serve as a competing mechanism that can ensure quality. The analysis of the model of repeated interaction between consumers and firms yields some interesting new outcomes while it encompasses the one-shot case originally examined by Glaeser and Shleifer. In this sense, it may be argued that the predictions of the contractual failure hypothesis apply in the special case where the long-run reputation mechanism cannot be sustained because interaction is not repeated or because of frictions in the flow of information. In more general circumstances, nonprofit status does not appear to be a necessary mechanism to overcome opportunistic behavior that arises because quality is unverifiable. Also, the multi-period version considered in this paper provides an explanation for the differences and variability in non-contractible quality across organizational types that have been identified in empirical studies of the child care sector.

The goal of this paper has not been to dismiss utterly the contractual failure hypothesis, only to challenge its scope as an explanation for the widespread presence of nonprofit organizations. The key implication of our analysis is that in many sectors, the existence of a large number of nonprofit firms cannot be explained with reference to their unique ability to mitigate problems of asymmetric information. In particular, we shouldn't expect it to be an important factor in industries where income from sales of services constitutes the largest source of revenue and where there is repeated interaction between consumers and providers, such as the child care sector discussed in the previous section and other social services. This does not preclude the theory from playing an important role in charitable services where donations are a significant source of revenues. Also, our analysis does not rule out the expropriation problem having significant implications on the relationship between the organization and various other economic actors such as its employees, volunteers, donors and

the different government agencies. Further research in these areas may prove fruitful in advancing our understanding of the role, advantages and evolution of the nonprofit sector. 


\section{References}

[1] Benoit, J.-P., Krishna, V., 1985. Finitely repeated games. Econometrica 53, 905-922.

[2] Blau, D., Currie, J., 2006. Preschool, day care, and after school care: Who's minding the kids? In: Hanushek, E., Welch, F. (Eds.). The Handbook of the Economics of Education, Vol. II. New York: North Holland, 1162-1275.

[3] Doherty, G., Friendly, M., Forer, B., 2002. Child care by default or design? An exploration of differences between non-profit and for-profit Canadian child care centres using the You Bet I Care! data sets. Childcare Resource and Research Unit, Occasional paper \#18.

[4] Easley, D., O'Hara, M., 1983. The economic role of the nonprofit firm. Bell Journal of Economics 14, 531-538.

[5] Glaeser, E., Shleifer, A., 2001. Not-for-profit entrepreneurs. Journal of Public Economics 81, 99-115.

[6] Hansmann, H., 1980. The role of nonprofit enterprise. Yale Law Journal 89, 835-901.

[7] Hart, O., Shleifer, A., Vishny, R., 1997. The proper scope of government: Theory and an application to prisons. Quarterly Journal of Economics 112, 1127-61.

[8] Horner, J., 2002. Reputation and competition. American Economic Review 92, 644-663.

[9] Klein, B., Leffler, K., 1981. The role of market forces in assuring contractual performance. Journal of Political Economy 89, 615-641.

[10] Krashinsky, M., 1998. Does auspice matter? The case of day care for children in Canada. In: Powell, W., Clemens, E. (Eds.). Private Action and the Public Good. New Haven: Yale University Press, 114-123.

[11] Nelson, P., 1970. Information and consumer behavior. Journal of Political Economy 78, 311329.

[12] Ortmann, A., Schlesinger, M., 2003. Trust, repute, and the role of nonprofit enterprise. In: Anheier, H., Ben-Ner, A. (Eds.). The Study of the Nonprofit Enterprise: Theories and Approaches. New York: Kluwer/Plenum, 77-114.

[13] Rose-Ackerman, S., 1996. Altruism, nonprofits and economic theory. Journal of Economic Literature 34, 701-28. 
[14] Shapiro, C., 1983. Premiums for high quality products as rents to reputation. Quarterly Journal of Economics 98, 659-680.

[15] Shapiro, C., 1986. Investment, moral hazard, and occupational licensing. Review of Economic Studies 53, 843-862.

[16] Tirole, J., 1988. The Theory of Industrial Organization. Cambridge: MIT Press.

[17] Weisbrod, B., 1988. The Nonprofit Economy. Cambridge: Harvard University Press. 